\title{
Educação ambiental não-formal em jornais da Região Celeiro do Rio Grande do Sul
}

\author{
Mayara Bonn', Divanilde Guerra², Luciane Sippert Lanzanova², Ramiro Pereira Bisognin², \\ Danni Maisa da Silva², Marciel Redin² \\ ' Acadêmica do Curso de Especialização em Gestão e Sustentabilidade Ambiental, Universidade Estadual do Rio Grande do Sul, \\ Unidade em Três Passos - RS. \\ E-mail: mayarabonn@gmail.com \\ ${ }^{2}$ Professor(a) Adjunto(a), Universidade Estadual do Rio Grande do Sul, Unidade em Três Passos - RS. \\ E-mail: divanilde-guerra@uergs.edu.br, luciane-sippert@uergs.edu.br, ramiro-bisognin@uergs.edu.br, danni-silva@uergs.edu.br, \\ marciel-redin@uergs.edu.br
}

\section{Resumo}

A Educação Ambiental está cada vez mais inserida no cotidiano da sociedade. Este artigo teve como objetivo analisar como jornais de circulação no Noroeste do Estado do Rio Grande do Sul noticiam assuntos sobre Meio Ambiente e Educação Ambiental. Realizou-se a avaliação e a quantificação de matérias sobre os temas nos jornais: "Atos e Fatos", "Atualidades", "O Celeiro" e "Novo Noroeste", utilizando a metodologia quanti-qualitativa. Foram analisados o total de notícias; temática abordada; presença das funções do Jornalismo Ambiental e das funções da Alfabetização Ecológica. Foram analisadas publicações do período de março a abril de 2017. Como resultado, verificou-se a presença da Educação Ambiental não-formal em 30 notícias encontradas nas editorias agricultura, rural, geral, entre outras, sendo observadas nove notícias no jornal "Atos e Fatos", oito no "O Celeiro", sete no "Novo Noroeste" e seis no "Atualidades". Observou-se também que o número de páginas totais dos jornais variou entre 14 e 40 páginas, com dedicação de no máximo duas páginas para o assunto deste estudo em cada notícia. As principais temáticas abordadas foram condição de produção de alimentos e grãos e reciclagem e mudanças climáticas. A função Informativa do Jornalismo Ambiental contou com maior ocorrência e os critérios da Alfabetização Ecológica que mais apareceram foram "Conhecimento", "Atitude e valores" e "Participação". Este estudo possibilitou a análise de jornais de circulação regional havendo a necessidade de incentivar a publicação de conteúdo sobre a Educação Ambiental de maneira a ampliar o número de notícias que tenham caráter não apenas formativo, mas também e principalmente pedagógico incentivando mudança de atitudes e consciência para a preservação e conservação do ambiente.

Palavras-chave: Meio Ambiente. Notícias. Jornalismo Impresso.

\section{Abstract}

\section{Non-formal environmental education in newspapers in the Celeiro Region, Rio Grande do Sul}

Environmental Education is increasingly inserted without everyday life in society. This paper had as objective to study how newspapers of circulation in the Northwest of the State of Rio Grande do Sul report subjects that deal with Environment and Environmental Education. The methodology used consisted in the evaluation and quantification of subjects related to the Environment and Environmental Education in the newspapers Atos e Fatos, Atualidades, $O$ Celeiro e Novo Noroeste. For that, the quantitative-qualitative methodology was used, and, later, the number of news items was analyzed; the theme addressed; the presence of the functions of Environmental Journalism and the use of the functions of Ecological Literacy. The period of analysis was chosen at random, being restricted to the months of March and April of 2017. As a result, the presence of non-formal Environmental Education was verified in thirty news items found in agricultural, rural, general, among others. Nine news items were observed in the newspaper "Atos e 
Fatos", eight in "O Celeiro", seven in "Novo Noroeste" and six in "Atualidades", it was also observed that the number of total pages of newspapers varied between 14 and 40 pages, with a maximum of two pages being devoted to the theme of this study in each news item. The main topics addressed were food and grain production, recycling and climate change conditions. The Informational Function of Environmental Journalism had more occurrence and the criteria of the Ecological Literacy that more appeared were Knowledge, Attitude and values and Participation. Therefore, this study was important because it made possible the analysis of newspapers of regional circulation where it was realized that it is necessary to develop non-formal Environmental Education, since its growth and dissemination will also entail the involvement of people in the discussion about the environment and new attitudes.

Keywords: Environment. News. Printed Journalism.

\section{Introdução}

O início do século $X X$ inaugurou uma crescente série de questionamentos sobre o futuro da humanidade. Isso em razão da saturação dos recursos naturais, do acelerado ritmo de desenvolvimento tecnológico, da devastação ambiental e do aumento populacional. Fatores que juntos demonstram a necessidade de planejar e executar ações que minimizem estes fatores (BELMONTE, 2004; COLOMBO, 20I0). Um dos caminhos foi a realização de conferências mundiais por parte da Organização das Nações Unidas (ONU) e da Organização das Nações Unidas para a Educação, a Ciência e a Cultura (UNESCO) para discutir temas relacionados ao Meio Ambiente e à sua proteção, dentre eles a importância da Educação Ambiental (MÜLLER, 1998). Para Dias (2010), a Conferência de Estocolmo, que foi realizada na Suécia, em 1972, é:

[...] um marco histórico-político internacional, decisivo para o surgimento de políticas de gerenciamento ambiental, a Conferência gerou a "Declaração sobre o Ambiente Humano", estabeleceu um "Plano de Ação Mundial” e, em particular, recomendou que deveria ser estabelecido um Programa Internacional de Educação Ambiental. A recomendação ${ }^{\circ}$ 96 da Conferência reconhecia o desenvolvimento da Educação Ambiental como elemento crítico para o combate à crise ambiental (DIAS, 20I0, p. 79).

Constata-se assim que na década de 1970 era abordada a necessidade de se pensar e modificar a questão ambiental, o que foi ganhando força ao longo da realização de diversas conferências e encontros mundiais, como a Conferência de Belgrado, a Conferência de Tbilisi, a Conferência de Moscou, a Eco-92 (ou Rio-92), a Rio + 10 e a Rio + 20, dentre outras (ARAÚJO, 2010 ; DIAS, 20 I0; CRETELLA NETO, 20I2). Foi no âmbito das Conferências Mundiais que se iniciou a discussão quanto à necessidade de elaborar uma política de Educação Ambiental, que no Brasil, anos mais tarde, viria a ter regulamentação legal na Constituição Brasileira de 1988, do artigo 225:

Art. 225. Todos têm direito ao meio ambiente ecologicamente equilibrado, bem de uso comum do povo e essencial à sadia qualidade de vida, impondo-se ao Poder Público e à coletividade o dever de defendê-lo e preservá-lo para as presentes e futuras gerações. $\S I^{\circ}$ Para assegurar a efetividade desse direito, incumbe ao Poder Público: [...] VI - Promover a educação ambiental em todos os níveis de ensino e a conscientização pública para a preservação do meio ambiente (BRASIL, I988).

Nesse sentido, Padilha (2010) afirma que a inserção de um capítulo sobre a temática ambiental e sua proteção na Constituição Brasileira significa um salto de qualidade no que diz respeito às normas de proteção ambiental, promoção da ecologia e realização de uma gestão ambiental sustentável. Da regulamentação legal, percebe-se a importância que é atribuída à prática da Educação Ambiental em todos os níveis de ensino e à conscientização pública. Isso posteriormente deu origem a Lei Federal n. 9.795/I999, que regulamentou e instituiu a Política Nacional de Educação Ambiental no Brasil. Segundo Milaré (20 I I, p. 63 I), "A educação ambiental passa a constituir um direito do cidadão, assemelhado aos direitos fundamentais, porquanto estreitamente ligado aos direitos e deveres constitucionais de cidadania". Com isso deve ser tratada como uma educação permanente em razão da sua importância. A partir da regulamentação proposta pela Lei Federal n० 9.795/1999, art. $\left.\right|^{\circ}$ : 
Entendem-se por educação ambiental os processos por meio dos quais o indivíduo e a coletividade constroem valores sociais, conhecimentos, habilidades, atitudes e competências voltadas para a conservação do meio ambiente, bem de uso comum do povo, essencial à sadia qualidade de vida e sua sustentabilidade (BRASIL, 1999, art. $1^{\circ}$ ).

Conforme fora discutido ao longo das conferências mundiais e posterior inserção da Constituição da República Federativa do Brasil de 1988, a Educação Ambiental é uma área de extrema importância composta por diversos processos voltados para a discussão e proteção ambiental. No mesmo sentido, Müller (1998) afirma que:

\begin{abstract}
A Educação Ambiental é uma forma de prática educacional sintonizada com a vida em sociedade. Ela só pode ser efetiva se todos os membros da sociedade participarem, de acordo com suas habilidades, das complexas e múltiplas tarefas de melhoria das relações das pessoas com seu meio ambiente. Isto só pode ser alcançado se as pessoas se conscientizarem do seu envolvimento e de suas responsabilidades (MÜLLER, 1998, p. 22).
\end{abstract}

De acordo com Müller (1998), a cada dia presenciam-se novas catástrofes e danos ambientais, de modo que se faz necessária a união de esforços para a geração de novas atitudes, hábitos e comportamentos. De acordo com Nunes (2005):

A preocupação com a destruição da natureza não é recente. $O$ que é recente é relacionar está destruição à ação e à visão dos seres humanos. $\bigcirc$ que hoje está sendo criticado não é simplesmente o modelo econômico ou político dominante, mas a percepção de mundo que nossa espécie, numa condição evolutiva privilegiada, desenvolveu e adotou como verdade absoluta, inquestionável e imutável, de superioridade, dominância e prevalência sobre as demais formas de vida e o conjunto do planeta terra (NUNES, 2005, p. I5).

E nesse panorama insere-se o jornalismo, como um meio de comunicação e difusão de informações e conhecimento. Sabe-se que a grande função dos meios de comunicação é a informação sobre os principais acontecimentos, o que segundo Caldas (2002, p. 30) "embora a imprensa seja um negócio comercial e a notícia uma mercadoria, a expectativa da sociedade exige que os fatos sejam relatados com isenção e independência editorial". Além disso, o autor ressalta ainda:

O jornalismo se distingue e caracteriza por ter uma relação direta com a história, por fazer o seu registro cotidiano, ainda quente e palpitante, é comum se ouvir 'deu no jornal'. Isso basta para mudar a feição de um acontecimento. Se saiu no impresso de fato ocorreu daquela maneira (CALDAS, 2002, p. 36).

Considerando ainda, o caráter que o Jornalismo possui e o seu papel dentro da Educação Ambiental não-formal, Bueno (2008) ressalta a existência de três funções desempenhadas pelo Jornalismo Ambiental, sendo elas a função informativa, a função pedagógica e a função política:

A função informativa preenche a necessidade que os cidadãos têm de estar em dia com os principais temas que abrangem a questão ambiental, considerando o impacto que determinadas posturas (hábitos de consumo, por exemplo), processos (efeito estufa, poluição do ar e água, contaminação por agrotóxicos, destruição da biodiversidade, etc.) e modelos (como o que privilegia o desenvolvimento a qualquer custo) tem sobre o meio ambiente e, por extensão, sobre a sua qualidade de vida. A função pedagógica diz respeito à explicitação das causas e soluções para os problemas ambientais e à indicação de caminhos (que incluem necessariamente a participação dos cidadãos) para a superação dos problemas ambientais. A função política (aqui entendida em seu sentido mais amplo e não obviamente restrita à sua instância meramente político-partidária) tem a ver com a mobilização dos cidadãos para fazer frente aos interesses que condicionam o agravamento da questão ambiental. Incluem-se entre esses interesses a ação de determi- 
nadas empresas e setores que, recorrentemente, têm penalizado o meio ambiente para favorecer os seus negócios (indústria agroquímica, de biotecnologia, de mineração, de papel e celulose, agropecuária, etc.). Incorpora também uma vigilância permanente com respeito à ação dos governantes (BUENO, 2008, p. 35 -36).

Daí a importância de se realizar um estudo sobre jornais de circulação regional no Noroeste do Estado do Rio Grande do Sul, verificando a presença da Educação Ambiental não-formal em suas publicações semanais. Deste modo, neste artigo objetivou-se analisar de que forma os jornais da região Celeiro - Noroeste do Estado do Rio Grande do Sul noticiam temas sobre Meio Ambiente e Educação Ambiental.

\section{Materiais e Métodos}

Este trabalho foi desenvolvido utilizando pesquisa quanti-qualitativa. Quantitativa porque inicialmente os dados obtidos foram tabulados e organizados em quadros e tabelas; e qualitativa, por possuir interesse prioritário na descrição, compreensão e análise dos dados obtidos (LAKATOS; MARCONI, 20I3). Foram registrados o número de notícias sobre o tema em cada jornal; qual a temática das notícias; a presença das funções do Jornalismo Ambiental; e o uso das funções da Alfabetização Ecológica.

Foram analisados quatro jornais impressos de circulação regional no Noroeste do Estado do Rio Grande do Sul: dois da cidade de Três Passos - "Atos e Fatos" e "Atualidades", um de Santo Augusto, "O Celeiro", e outro de Humaitá, "Novo Noroeste", buscando-se compreender como estes semanários noticiam Meio Ambiente e Educação Ambiental. Todos os jornais são semanais e distribuídos às sextas-feiras, tendo sido fundados em 1997, 1976, 1970 e 2006, respectivamente. Foram analisados exemplares do período de março e abril de 2017 , totalizando a análise de 30 notícias das nove edições veiculadas no período.

A partir do registro das matérias jornalísticas nas edições de cada jornal, foi possível estudá-las com base na Teoria da Análise de Conteúdo proposta por Bardin (2004), Funções do Jornalismo Ambiental descrita por Bueno (2008) e Alfabetização Ecológica proposta por Nunes (2005), de modo a subdividir os dados em categorias de análise. Segundo Bardin (2004, p. 32), a análise de conteúdo "é o método das categorias, espécies de gavetas ou rubricas significativas que permitem a classificação dos elementos de significação constitutivos da mensagem".

Berelson (apud Bardin, 2004, p. 36) afira que a análise de conteúdo é "uma técnica de investigação que através de uma descrição objetiva, sistemática e quantitativa do conteúdo manifesto das comunicações, tem por finalidade a interpretação destas comunicações”. Bardin (2004, p. 38) afirma que a análise de conteúdo "aparece como um conjunto de técnicas de análise das comunicações, que utiliza procedimentos sistemáticos e objetivos de descrição do conteúdo das mensagens". Bardin (2004) estabelece que a Análise de Conteúdo passa por três fases, quais sejam, a pré-análise, com a escolha do material, a exploração do material e, por fim o tratamento dos resultados, a inferência e a interpretação. Herscovitz (2008, p. 125), afirma que "a característica híbrida da análise de conteúdo - pode ser vista como um método que reúne elementos quantitativos e qualitativos - coloca-a num gueto metodológico de onde ela sai reforçada e não enfraquecida".

A análise dos dados foi realizada com base nas funções do jornalismo ambiental, segundo Bueno (2008), ou seja, foi considerado se as matérias apresentavam teor informativo com os principais temas que abrangem a questão ambiental, função pedagógica com a identificação das causas e possíveis soluções para os problemas ambientais e, por fim, a função política, que busca identificar a mobilização dos cidadãos perante os problemas ambientais.

Por último, realizou-se a classificação das matérias com base nos componentes da alfabetização ecológica proposta por Nunes (2005). Para tanto, utilizou-se como critérios: (A) consciência ecológica; (B) conhecimento; (C) atitude e valores; (D) aptidão; (E) capacidade de avaliação; e (F) participação.

\section{Resultados e Discussão}

No total foram analisadas 30 notícias sobre o tema ambiental nos jornais "Atos e Fatos" $(n=9)$, "O Celeiro" ( $n=8)$, "Novo Noroeste" $(n=7)$ e "Atualidades" $(n=6)$. Considerando o volume de informações apresentados nos jornais entre 14 e 40 páginas, registrou-se que o máximo dedicado a temática deste estudo foi de duas páginas ("O Celeiro, variando entre 28 e 40 páginas de conteúdo geral). 
Cabe salientar que apesar da inserção da internet em nosso cotidiano, o jornalismo impresso, realizado por jornais de circulação diária ou semanal, possui grande grau de credibilidade junto aos leitores. Nesse sentido, Mattozo e Camargo (2005) apresentam uma pesquisa realizada pelo Data Folha, em junho de 200 I, nas cidades de Porto Alegre, São Paulo, Rio de Janeiro, Recife e Brasília sobre o tema "credibilidade institucional", e de acordo com os dados obtidos o jornalismo impresso ficou em segundo lugar (I5\% de credibilidade), atrás apenas da igreja católica (30\%) (total de 1605 entrevistas).

O número de páginas de cada edição é relevante, pois demonstra que os jornais possuíam um espaço razoável para publicação de conteúdo, porém sem destaque ou garantia de espaço específico para a temática ambiental. Bacchetta (2000, p. 18) afirma que "o jornalismo ambiental é um dos gêneros mais amplos e complexos do jornalismo", que pode contribuir com a educação ambiental quando possui seu espaço assegurado nos meios de comunicação e, desta forma, promovendo a Educação Ambiental não-formal. Fonseca (2004, p. 137) acredita que "Ao contextualizar, informar e traduzir as pesquisas para uma linguagem mais acessível" o jornalismo ambiental contribui para a compreensão da população quando se refere a assuntos mais especializados. No mesmo sentido, Gama e Dadalto (2009, p. 02) afirmam que "A participação da atividade jornalística na realidade social ocorre desde a determinação do que é notícia até sua ressignificação pelo receptor". Desta forma, se existir uma preocupação por parte dos jornalistas em se produzir um discurso abordando o tema meio ambiente, é possível que se consiga criar um maior espaço de discussão para toda a sociedade. Isso vai ao encontro do que propõe a Lei Federal $n^{\circ} .9 .795 / 1999$ quando em seu artigo 13 contempla a Educação Ambiental Não-Formal, que trata de ações e práticas educativas voltadas para a sociedade, inclusive com a regulamentação da difusão dessa temática pelos meios de comunicação de massa.

A Figura I apresenta as editorias em que a temática ambiental apresentou notícias em cada jornal pesquisado. No que se refere ao jornal Atos e Fatos, as notícias relacionadas a área ambiental estiveram presentes em editorias diversas, como Agricultura, com seis notícias, Variedades, com uma notícia, Cadernos Especiais, com uma notícia e Geral, com uma notícia. Já o jornal Atualidades veiculou suas matérias nas editorias Especial, com duas publicações, Rural, com três notícias, e Região, com uma notícia. O jornal Novo Noroeste utilizou-se da editoria Rural para apresentar suas notícias e, também, utilizou a editoria Geral. Por fim, o jornal O Celeiro publicou suas notícias na editoria Geral, com seis notícias, e no Editorial do Jornal, com duas publicações.

Figura I - Notícias por editoria com a temática ambiental por jornal analisado na pesquisa.

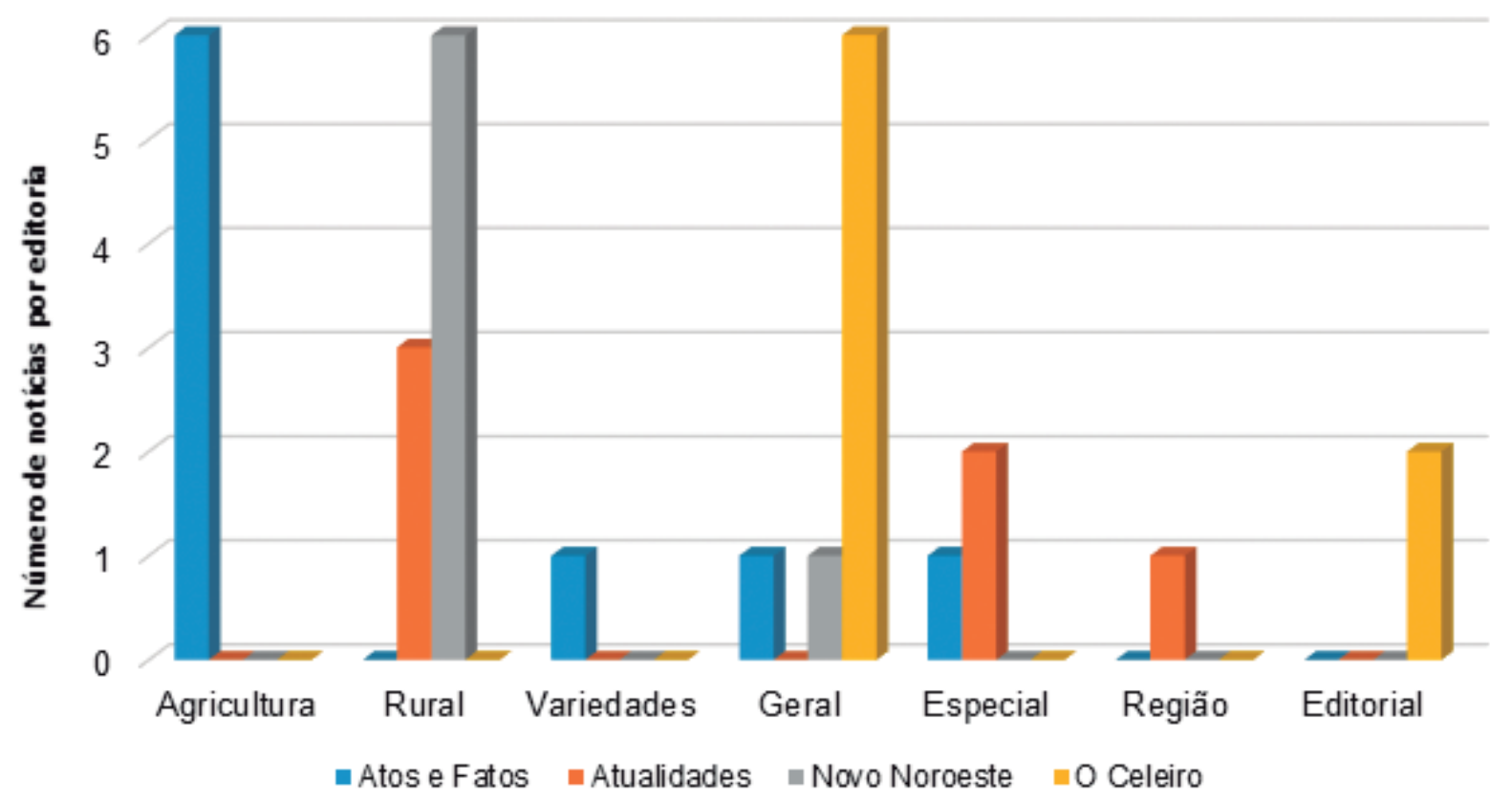

Fonte: Autores, 2019

A partir destes dados, percebe-se que não há uma editoria específica para o Jornalismo Ambiental em nenhum dos jornais pesquisados. O que se observa é o uso das editorias como Rural, Agricultura, Geral, Especial e até mesmo a área do Editorial do Jornal para englobar temas relacionados à temática ambiental, 
muito embora se diferencie do que seria a educação ambiental, conforme Müller (1998) havia descrito, no sentido de que a prática da Educação Ambiental seria uma prática sintonizada com a vida em sociedade. Nesse sentido, Bardin (2004, p. I I 2) afirma que "Classificar elementos em categorias impóe a investigação do que cada um deles tem em comum com os outros. $O$ que vai permitir o seu agrupamento é a parte comum existente entre eles". E nesse caso, os dados encontrados no estudo demonstram que embora existam iniciativas de notícias relacionadas a temática ambiental, nenhum dos jornais, dentro do período de análise, apresentou as notícias em uma editoria específica como "Meio Ambiente" ou outra nomenclatura.

Após a observação quanto as editorias em que foram veiculadas as notícias, passou-se a observação de quais seriam as temáticas abordadas pelas notícias, que poderiam ser consideradas como correlacionadas a temática ambiental. Nesse sentido, Bueno (2008) apresenta um conjunto de temas que acredita estarem presentes no Jornalismo Ambiental:

O desenvolvimento e a proteção da fauna e da flora; a diversidade biológica ou biodiversidade; a poluição em suas várias formas (atmosférica, visual, sonora, etc.); as mudanças climáticas; as condições da água e do solo; o consumo consciente; a sociodiversidade, que prevê a relação do homem com o seu entorno; os resíduos domésticos e o lixo industrial; as condições de produção de alimentos (a agroecologia, os transgênicos e os aditivos alimentares, por exemplo); a produção, conservação e utilização de energia; as condições de habitação (favelização, edifícios doentes, etc.); as comunidades biológicas (os biomas e sua preservação); o crescimento e a regulação populacional; a embalagem (ecodesign) e a reciclagem; o saneamento e $\circ$ tratamento de efluentes industriais; os agrotóxicos e os fertilizantes químicos em geral; a ocupação desordenada do solo urbano; o conhecimento e o saber das populações tradicionais e assim por diante (BUENO, 2008, p. 35).

A partir dos temas elencados por Bueno (2008), foi possível verificar no material analisado quais as temáticas presentes nas notícias veiculadas, conforme Tabela $\mathrm{I}$.

Tabela I - Notícias por temáticas nos jornais analisados na pesquisa.

\begin{tabular}{|c|c|c|c|c|}
\hline Temas Jornais & Atos e Fatos & Atualidades & Novo Noroeste & O Celeiro \\
\hline Mudanças climáticas & & I (chuvas) & & $\begin{array}{l}3 \text { (produção de lixo, uso } \\
\text { da água, podas urbanas) }\end{array}$ \\
\hline Condições de água e solo & $\begin{array}{c}2 \text { (pastagens inverno, } \\
\text { irrigação) }\end{array}$ & & & $\begin{array}{l}\text { I (repovoamento de } \\
\text { rio) }\end{array}$ \\
\hline $\begin{array}{l}\text { Condições de produção } \\
\text { de alimentos e grãos }\end{array}$ & $\begin{array}{l}4 \text { (horta e bem-estar, } \\
\text { moranga, grãos, soja) }\end{array}$ & 2 (soja, horta em casa) & $\begin{array}{l}4 \text { (abóboras, soja, } \\
\text { amendoim) }\end{array}$ & $\begin{array}{l}4 \text { (produção leiteira, } \\
\text { produção de soja) }\end{array}$ \\
\hline Produção de energia & I (fotovoltaica) & & & \\
\hline $\begin{array}{c}\text { Comunidades biológicas } \\
\text { - biomas }\end{array}$ & $\begin{array}{l}\text { I (reserva Florestal } \\
\text { do Turvo) }\end{array}$ & & & \\
\hline Reciclagem & I (pneus) & & 3 (coleta seletiva) & \\
\hline Agropecuária & & $\begin{array}{l}3 \text { (crescimento do se- } \\
\text { tor, pecuária, lavouras) }\end{array}$ & & \\
\hline
\end{tabular}

Fonte: Autores, 2019.

Observou-se uma predominância de notícias relacionadas a condição de produção de alimentos e grãos, com quatorze notícias, em segundo lugar estão matérias relacionadas a temática reciclagem e as mudanças climáticas, ambas com quatro notícias, em terceiro estão os temas condições de água e solo e agropecuária, que apresentaram três notícias, e com apenas uma notícia de cada estão os temas produção de energia e comunidades biológicas. Segundo Bueno (2008), esses temas estão presentes no dia a dia da sociedade e, ao serem retratados nos jornais, possibilitam que o leitor compreenda que a notícia se relaciona com a temática ambiental. São assuntos que se inserem na área ambiental, porém não tratam especificamente sobre a temática, pois possuem um viés mais próximo da agricultura. Muitas vezes, outras notícias trazem informações e conhecimento relacionados a mudanças de atitude, como o reaproveitamento de pneus para construção de 
pufes, a utilização de energia solar fotovoltaica, como forma de economia e qualidade, além da divulgação dos benefícios da construção de hortas caseiras para alimentos, entre outros exemplos encontrados durante o período analisado.

É importante destacar que a Educação Ambiental e o Jornalismo Ambiental são também assuntos que podem ser considerados como uma prática especializada, que precisa ser elaborada com grande apuração e conhecimento, conforme afirma Tavares (2009):

Pensar em jornalismo especializado diz respeito a ter de buscar um consenso sobre três manifestações empíricas referentes às suas especializações. I) A especialização pode estar associada a meios de comunicação específicos (jornalismo televisivo, radiofônico, ciberjornalismo, etc) e 2) a temas (jornalismo econômico, ambiental, esportivo etc), ou pode estar associada 3) aos produtos resultantes da junção de ambos (jornalismo esportivo radiofônico, jornalismo cultural impresso, etc). (TAVARES, 2009, p. 09)

Tavares (2009, p. 09) ainda acrescenta que ao jornalismo especializado deve ser atribuído o papel de "Intermediar saberes especializados na sociedade, construindo um tipo de discurso que, noticioso, ou 'apenas' informacional, promova um outro tipo de conhecimento que se funda na compreensão conjunta do universo científico e do senso comum".

A função Informativa predominou com $54 \%$ de ocorrências, as funções Informativa e Pedagógica foram encontradas em $43 \%$ das notícias, e apenas $3 \%$ apresentaram a função Pedagógica. Não foi verificada a presença da função Política nas notícias. A predominância das funções Informativa e Informativa/Pedagógica demonstra a necessidade de se aprofundar na elaboração de notícias dentro do Jornalismo Ambiental, pois consideramos que a função Pedagógica foi pouco contemplada no período analisado, e a função Política sequer foi contemplada. A predominância da função Informativa também ocorre em razão da periodicidade dos jornais, pois todos são semanais, publicados na sexta-feira. Além disso, percebe-se que possuem uma linha editorial onde predominam notícias factuais, ou seja, que tratam de fatos que aconteceram naquela semana, reduzindo o aprofundamento no tema. Vale ressaltar que o registro da função pedagógica, mesmo que em menor quantidade do que se esperava, já é um ponto positivo atendendo a legislação que regula a Educação Ambiental, item maior "formação e mobilização de cidadania ambiental" (BERNA, 2008, p. 89).

Um exemplo de função pedagógica é a matéria do Jornal Atos e Fatos (Edição I022, p. II, 03/03/20 I7) que orienta como o leitor pode fazer um puff utilizando pneus de automóveis. A comunidade é incentivada a realizar ações que beneficiem o meio ambiente, como a reutilização de materiais descartados. Já o Jornal Atualidades apresentou uma notícia referente à construção de uma horta em casa, para a produção de legumes e verduras sem o uso de agrotóxicos, e apresentou sugestões para as diferentes residências. Assim, conforme Bueno (2008) a função Pedagógica é um meio de expressar as causas e soluções para problemas, com a apresentação de oportunidades de participação do cidadão. Mesmo com a inserção da função pedagógica nos jornais da região Noroeste ainda predomina a cobertura factual, baseada na transmissão de informações aos leitores.

Em seu estudo, Belmonte (2004, p. 18) afirma que "O que predomina no noticiário sobre os problemas urbanos é a cobertura pontual, com bastante destaque para momentos de crise e pouco espaço para análises, investigações, interpretações e apresentação de novos caminhos". Esta cobertura acaba prejudicando o público, pois o alarde é prejudicial para a informação, já que em algumas situações provoca pânico e induz à má utilização de informações veiculadas, podendo, ainda, gerar medo e não reflexão (BELMONTE, 2004; GIRARDI; MORAES; LOOSE, 20I2).

Nesse sentido, Berna (2008) afirma que:

A informação ambiental de qualidade e em quantidade é ferramenta indispensável para a formação e mobilização da cidadania ambiental. Por outro lado, informações ambientais deficientes, mentirosas ou incompletas podem levar à desmobilização da cidadania. A democratização da informação ambiental é fundamental para o exercício pleno da cidadania crítica e participativa, pois quando as pessoas, povo, ou as organizações não dispõem de informação de qualidade, fica comprometida a capacidade de fazer escolhas entre as diferentes alternativas e caminhos (BERNA, 2008, p. 89 - 90). 
Aqui se percebe a correlação que propõe a Lei Federal n. 9795/ I999, quando expressa a necessidade de se desenvolver a Educação Ambiental não-formal por meio de uma de suas vias, qual seja, o jornalismo impresso produzido por jornais. Dornelles (2008) posiciona-se quanto à necessidade de se desenvolver uma pauta ambiental com uma postura e função pedagógica, por meio da qual se disseminem informações, conhecimentos e vivências, de modo a ofertar condições para o cidadão comum participar do debate.

Além disso, pensando no desenvolvimento da Educação Ambiental e formas para isso, Nunes (2005) propõe a Alfabetização Ecológica, que tem por conceito:

O conhecimento necessário para a compreensão da forma de organização da vida na terra, o que vai propiciar aos indivíduos momentos de reflexão e sensibilização que contribuem na formação de valores e atitudes. A ação prática da proposta metodológica da alfabetização ecológica contribui no desenvolvimento de capacidades, habilidade e aptidões (NUNES, 2005, p. 45).

A autora acredita que a partir da Alfabetização Ecológica, realizada dentro da Educação Ambiental, poderá haver melhora da qualidade de vida das pessoas e ampliação da visão da sociedade quanto ao tema. Por sua vez, Nunes (2005) acredita que:

O resultado do esforço educativo nessa área tem referência para que o processo pedagógico intencione auxiliar seus destinatários a adquirirem: a - consciência ecológica e maior sensibilidade da importância do ambiente e dos problemas conexos. A consciência é o resultado do processo de reflexão-ação-reflexão; $b$ - conhecimento - indispensável à compreensão básica do ambiente em sua totalidade, dos problemas conexos e da presença e função da humanidade nele; c - Atitude e valores - sociais e um profundo interesse pelo ambiente, que os impulsione a participar ativamente em sua proteção e melhoria; d - Aptidão - necessária para resolver os problemas ambientais, prevenindo a ocorrência de novos problemas; e - Capacidade de avaliação - para determinar a validade das ações de educação ambiental, em função da sua aderência à situação ecológica, política, econômica, social, educacional, e paisagística da realidade; $\mathrm{f}$ - Participação - na elaboração, implantação e no desenvolvimento de programas de educação ambiental, no sentido de estimular a responsabilidade, a consciência da urgente necessidade de dar atenção aos problemas do meio ambiente, e a gestão participativa (NUNES, 2005, p. 45 -46).

Müller (1998, p. 26) categoriza os objetivos/processos em cinco categorias: "Consciência, conhecimento, comportamento, habilidades e participação", e, de igual modo, o resultado almejado é a integração entre homem e natureza por meio da utilização e inserção desses critérios.

A partir disso, foi possível elaborar a Figura 2, na qual são apresentados os dados referentes aos critérios descritos por Nunes (2005), como componentes da Alfabetização Ecológica, após análise dos quatro jornais e suas edições individualmente, sendo eles Jornal Atos e Fatos, Atualidades, Novo Noroeste, e O Celeiro, respectivamente.

Como observado na Figura 2, o jornal Atos e Fatos apresentou maior incidência do critério "Conhecimento", com oito notícias. O critério "Atitude e Valores" ficou em segundo lugar, com sete notícias. Em terceiro lugar está o critério Participação, com seis notícias, seguido pelo critério "Aptidão", com cinco notícias, critério "Consciência Ecológica" com quatro notícias e, por fim, o critério "Capacidade de Avaliação", com três notícias. Cabe salientar que mais de um critério foi encontrado em uma mesma notícia (sobreposição), demonstrando a sua correlação. $O$ jornal Atualidades apresentou o maior número de notícias no critério "Conhecimento" (seis notícias), em segundo lugar o critério "Atitude e Valores" (cinco notícias), em terceiro o critério "Consciência Ecológica" (duas notícias), seguido pelos critérios "Aptidão, Capacidade de Avaliação e Participação" (uma notícia cada). Novamente, mais de um critério foi encontrado na mesma notícia, demonstrando a sua correlação.

O jornal Novo Noroeste apresentou em maior número a ocorrência do critério "Conhecimento", com seis notícias, em segundo o critério "Atitude e Valores", com cinco notícias, em terceiro os critérios "Aptidão, Capacidade de avaliação e Participação", todos com quatro notícias e, por fim, o critério "Consciência Ecológica”, com três notícias. 
Figura 2 - Número de critérios encontrados como componentes da Alfabetização Ecológica nos Jornais Atos e Fatos, Atualidades, Novo Noroeste e O Celeiro, de março a abril de 2017, na região Noroeste do Rio Grande do Sul.

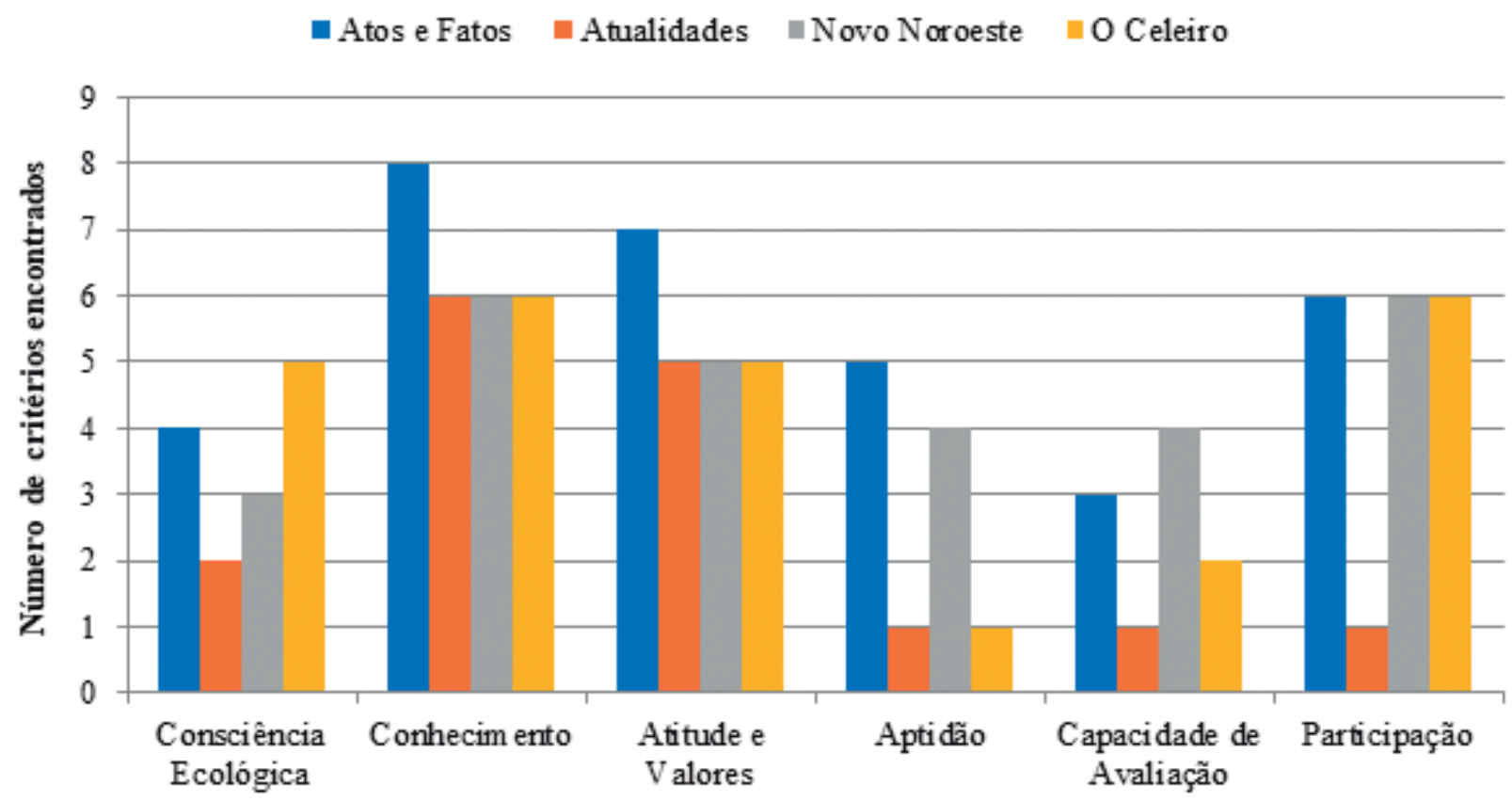

Critérios de Alfabetização Ecológica

Nesta mesma perspectiva, conforme Figura 2, o jornal O Celeiro apresentou em maior número a ocorrência do critério "Conhecimento", com seis notícias, em segundo os critérios "Consciência Ecológica" e "Atitude e Valores", ambos com cinco notícias, seguindo pelo critério "Capacidade de Avaliação", com duas notícias e, por fim, o critério "Aptidão" com uma ocorrência. Salienta-se mais uma vez que, mais de um critério foi encontrado na mesma notícia, demonstrando a sua correlação.

Nunes (2005, p. 39) afirma que "A educação ambiental deve partir da crítica ao modelo de pensamento que adotamos no presente e que determina o nosso modus vivendi, que se reflete em todas as áreas de nossa vida". Desta forma, observando o processo proposto com base nos itens da Alfabetização Ecológica, tem-se uma importante contribuição no que diz respeito a efetiva realização da Educação Ambiental não-formal por meio da veiculação de notícias pelos jornais analisados. Conforme pode ser observado na Figura 2, os jornais pesquisados já apresentam uma produção de conteúdo que possui a presença de algum dos critérios da Alfabetização Ecológica. Destaca-se a presença dos temas Conhecimento, Atitude e Valores e Participação, em maior quantidade, o que demonstra a preocupação das notícias em transmitir conhecimentos aos seus leitores, que muitas vezes estão imbuídos de atitudes e valores, capazes de transformar a vida cotidiana em sociedade. Para Nunes (2005), essa relação entre Alfabetização Ecológica e Educação Ambiental é extremamente necessária para a construção de uma nova leitura de mundo onde se insira a consciência ecológica e ambiental frente aos problemas ambientais existentes e as ações do homem.

Cuida-se de uma construção de cidadania crítica e atuante, o que pode acontecer por meio da Educação Ambiental não-formal desenvolvida pelos jornais impressos em conjunto com outras ações. Nesse sentido, Nunes (2005, p. 35) afirma que "A alfabetização ambiental leva à construção de uma cidadania ambientalmente responsável, que trabalha intensamente sobre temas e preocupações no que concerne à vida cotidiana das pessoas". No mesmo sentido, Reigota (1998, p. 24) afirma que "A educação ambiental precisa cada vez mais manter a sua autonomia e independência crítica; só assim poderá ser uma real possibilidade de mobilização social e participação cidadã frente aos complexos problemas ambientais".

\section{Considerações Finais}

Constatou-se que no período analisado os jornais apresentaram notícias relacionadas à temática ambiental em suas edições, mas a partir dos dados encontrados verificou-se que essa cobertura possui características mais informativas e factuais, pois não há uma sequência ou continuação de notícias nas edições posteriores. 
A temática ambiental não possui uma editoria específica onde seus temas possam ser discutidos, mas está inserida em outras editorias como Rural, Agricultura, Geral, Especial e Variedades.

Além disso, percebeu-se que os assuntos veiculados que se correlacionam com a temática ambiental são muito próximos da temática agricultura, com destaque para notícias sobre a produção de alimentos e a agropecuária. Outro tema que apresentou um bom número de notícias está relacionado às mudanças climáticas.

No que diz respeito aos critérios de alfabetização ecológica, os jornais apresentaram em suas notícias vários critérios correlacionados em uma mesma notícia, o que demonstra que existe sim um entendimento e veiculação da temática ambiental, mesmo que isso ainda não tenha o destaque e a atenção que o tema exige. O fato dos critérios Conhecimento, Atitude e Valores e Participação se apresentarem em maior número, demonstra que os jornais apresentam notícias que possuem ideias e fatos que colaboram com a construção de novas ideias e ações para o meio ambiente.

Por fim, o presente estudo foi importante na medida em que possibilitou a realização de uma análise dos jornais de circulação regional onde foi possível perceber que ainda é preciso desenvolver-se a Educação Ambiental não-formal, vez que o seu crescimento também acarretará no envolvimento das pessoas e sua conscientização quanto a importância de se discutir e promover novas ações em relação ao meio ambiente. Ademais, em razão da importância da temática ambiental, os jornais deveriam conceder maior espaço e divulgação de ações e notícias de forma pedagógica e com a apresentação de possibilidades para os leitores, contando com a inserção de especialistas na área ambiental para dar ainda mais credibilidade as notícias.

\section{Referências}

ARAÚJO, A. R. Educação Ambiental e Sustentabilidade: desafios para a sua aplicabilidade. 20I0. 77 p. (Monografia) Especialização em Gestão e Manejo Ambiental em Sistemas Agrícolas. Universidade Federal de Lavras, Minas Gerais, 2010.

BARDIN, L. Análise de conteúdo. 3. ed. Lisboa: Edições 70, 2004.

BACCHETTA, V. L. Ciudadania planetaria: temas y desafios del periodismo ambiental. Federación Internacional de Periodistas Ambientales/Fundación Friedrich Ebert, 2000.

BELMONTE, R. V. Cidades em mutação: menos catástrofes e mais ecojornalismo. In: BOAS, S. V. (Org.). Formação e informação ambiental: jornalismo para iniciados e leigos. São Paulo: Summus, 2004. p. I I I-I 48.

BERNA, V. S. Desafios para a comunicação ambiental. In: GIRARDI, Ilza Maria; SCHWAAB, R.T. (Org.). Jornalismo ambiental: desafios e reflexões. Porto Alegre: Dom Quixote, 2008. p. 89-104.

BRASIL. Constituição da República Federativa do Brasil de 1988. 1988. Disponível em: http://www.planalto.gov. br/ccivil_03/constituicao/constituicaocompilado.htm. Acesso em: 3I ago 2019.

BRASIL. Lei 9.795, de 27 de abril de 1999. Disponível em: http://www.planalto.gov.br/ccivil_03/leis/L9795.htm. Acesso em 31 maio 2019.

BUENO, W. C. Jornalismo ambiental: explorando além do conceito. In: GIRARDI, I. M.; SCHWAAB, R. T. (Org.). Jornalismo ambiental: desafios e reflexões. Porto Alegre: Dom Quixote, 2008. p. 105-I I8.

CALDAS, A. O desafio do velho jornal é preservar seus valores. In: CALDAS, A. (org) Deu no jornal: o jornalismo impresso na era da internet. Rio de Janeiro: Ed. PUC-Rio: São Paulo: Loyola, 2002.

COLOMBO, M. E. Jornalismo Ambiental: a sua história e conceito no contexto social. Intercom 2010. Artigo. Disponível em: http://www.intercom.org.br/papers/nacionais/2010/resumos/R5-2674-I.pdf. Acesso em: 24 jun. 2019.

CRETELLA NETO, J. Curso de direito internacional do meio ambiente. São Paulo: Saraiva. 2012. 936p.

DIAS, G. F. Educação Ambiental: princípios e práticas. 2010. 9 ed. São Paulo: Gaia.

DORNELLES, B. O fim da objetividade e da neutralidade no jornalismo cívico e no ambiental. In: GIRARDI, I M; SCHWAAB, R.T. (Org.). Jornalismo ambiental: desafios e reflexões. Porto Alegre: Dom Quixote, 2008. p.43-55.

FONSECA, A. A. A magnitude do problema em uma experiência concreta. In: BOAS, S. V. (Org.). Formação e informação ambiental: jornalismo para iniciados e leigos. São Paulo: Summus, 2004. p. II I- I 48.

FONSECA, A. A. Água de uma fonte só. In: VILAS BOAS, S. Formação \& informação ambiental: jornalismo para iniciados e leigos. São Paulo: Summus, 2004, p. III - 148. 
GAMA, R. M.; DADALTO, M. C. A notícia como construção social no universo jornalístico. Bocc. 2009. Artigo. Disponível em: http://bocc.ubi.pt/pag/velha-dadalto-gama-noticia-como-construcao-social.pdf. Acesso em I2 ago. 2019.

GIRARDI, I. M. T.; MOARES, C. H.; LOOSE, E. B. Bases do jornalismo ambiental e os desafios para a cobertura da Rio+20. Razon e Palabra. V. I, p. 0 I-29. 20I2. Disponível em: < http://www.razonypalabra.org.mx/N/N79/M79/0 I TourinhoHerteBeling_M79.pdf $>$. Acesso em: 17 de maio 2019.

HERSCOVITZ, H. G. Análise de conteúdo em jornalismo. In: LAGO, C.; BENETTI, M. (Org). Metodologia de pesquisa em jornalismo. 2. ed. Petrópolis: 2008. p. I23-I42.

LAKATOS, E. M.; MARCONI, M. A. Metodologia do trabalho científico: procedimentos básicos, pesquisa bibliográfica, projeto e relatório publicações e trabalhos científicos. 7 ed. São Paulo: Atlas, 2013.

MATTOZO, V.; CAMARGO, C. Energia, ambiente e mídia: qual é a questão? Florianópolis: UFSC, 2005.

MILARE, E. D. Direito do ambiente: a gestão ambiental em foco - doutrina, jurisprudência, glossário. 7. ed. São Paulo: Revista dos Tribunais, 20II.

MÜLLER, J. Educação Ambiental: diretrizes para a prática pedagógica. Porto Alegre: Nova Prova, 1998. 146p.

NUNES, E R M. Alfabetização ecológica: um caminho para a sustentabilidade. Porto Alegre: Ed. Do Autor. 2005.

PADILHA, S. N. Fundamentos constitucionais do direito ambiental brasileiro. Rio de Janeiro: Elsevier. 2010.

REIGOTA, M. Educação Ambiental: fragmentos de sua história no Brasil. In: NOAL, F. O.; REIGOTA, M. BARCELOS, V. de L. Tendências da Educação Ambiental Brasileira. Santa Cruz do Sul: EDUNISC, 1998.

TAVARES, F. O jornalismo especializado e a especialização periodística. Estudos em Comunicação, número 5, p. I I 5- I 33. Maio de 2009. Disponível em: http://www.ec.ubi.pt/ec/05/pdf/06-tavares-acontecimento.pdf. Acesso em: I8 jun. 20 I9. 